\title{
ENTRE A ELEGIA, O JAMBO E A MÉLICA: NOTA SOBRE OS ESTUDOS MAIS RECENTES DE UM GRUPO DE PESQUISA
}

\begin{abstract}
Giuliana Ragusa*
Recebido em: 06/10/2019

Aprovado em: 21/10/2019

BETWEEN ELEGY, LAMBUS AND MELIC POETRY: NOTES ON RECENT STUDIES OF A RESEARCH GROUP
\end{abstract}

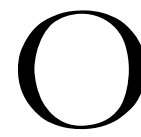
grupo de pesquisa (GPq) Estudos sobre jambo, elegia, mélica e música na antiguidade clássica foi criado em 2002 pela Profa. Dra. Paula da Cunha Corrêa (USP-FFLCH), pesquisadora bolsista de Produtividade do $\mathrm{CNPq}$, sua líder. Integrei-o primeiramente como estudante, tendo passado, após o doutorado em 2008, à coliderança. Como membros, agrega pesquisadores que foram alunos da Profa. Paula Corrêa e hoje atuam em instituições de ensino superior no país, além de colegas de mais longa data. Como colaboradores estrangeiros, agrega colegas com os quais o intercâmbio tem sido mais estreito. Como estudantes, o maior conjunto, temos reunido alunos da USP e de outras instituições, que realizam iniciação científica, mestrado ou doutorado, com pesquisas coerentes com o perfil e o objeto a que se dedica o grupo. E qual é o perfil? Qual é o objeto?

Se fôssemos definir o seu objeto por exclusão, o GPq se dedica aos gêneros poéticos não-hexamétricos e não-dramáticos que viveram seu auge na Grécia arcaica (c. 800-480 a.C.), mas ainda se estendem à era clássica (c. 480-323 a.C.): a poesia jâmbica, a poesia elegíaca e a poesia mélica (a lírica, na acepção antiga da canção para performance ao som da lira). Sob uma abordagem metodológica que privilegia a análise filológica dos textos vistos em seus contextos histórico-culturais, em suas fontes e em seus gêneros, em busca do rigor e da precisão no tratamento dos corpora, o grupo se desdobra em duas linhas de pesquisa. A linha "Jambo, elegia, mélica e música: teoria dos gêneros e estudos temáticos", que investiga a especificidade dos gêneros e das teorias poéticas antigas, e realiza estudos temáticos de
* Professora Livredocente de língua e literatura grega, Universidade de São Paulo.

gragusa@usp.br

: 
obras de poetas do corpus; a linha "Jambo, elegia, mélica e música: tradução e comentário", que contempla poetas da era arcaica à helenística, disponibilizando suas obras aos leitores interessados, em traduções em geral acadêmicas.

As publicações de trabalhos por parte dos integrantes do GPq têm sido constantes, em livros e periódicos. São estudos concentrados ou mais aprofundados, e antologias de traduções comentadas. E o esforço para acrescer aos trabalhos já publicados novos títulos é permanente. Destacam-se também os trabalhos de conclusão de formação dos alunos, sobretudo os de mestrado e doutorado, com suas teses e dissertações. E começam a ser realizados trabalhos em parceria entre os membros do grupo, como a Antologia de elegia grega arcaica, que preparei com o Prof. Dr. Rafael Brunhara (UFRGS), prevista para publicação em 2020, pela Ateliê Editorial. Nela, poetas são apresentados, o gênero é discutido e os textos selecionados - os mais conhecidos e os menos explorados - são traduzidos, anotados, comentados.

Como livros já publicados, podem ser indicados, de Paula Corrêa: Harmonia, mito e música na Grécia antiga (Humanitas, 2003), Armas e varões. A guerra na lírica de Arquíloco (Editora da Unesp, 2009, $2^{\mathrm{a}}$ ed. revista e ampliada) e Um bestiário arcaico. Fábulas e imagens na poesia de Arquíloco (Editora da Unicamp, 2010). De José Marcos Macedo, A palavra ofertada. Uma análise retórica e formal dos hinos gregos e da tradição hínica grega e indiana (Editora da Unicamp, 2010). De Rafael Brunhara, As elegias de Tirteu. Poesia e performance na Esparta arcaica (Humanitas, 2014). De Giuliana Ragusa, Fragmentos de uma deusa. A representação de Afrodite na lírica de Safo (Editora da Unicamp, 2005), Lira, mito e erotismo. A representação de Afrodite na mélica grega arcaica (Editora da Unicamp, 2010), Safo de Lesbos. Hino a Afrodite e outros poemas (org. e trad., Editora Hedra, 2011), Lira grega: antologia de poesia arcaica (org. e trad., Editora Hedra, 2013).

Menos constantes têm sido os encontros formais, que, todavia, queremos tornar mais regulares nestes próximos tempos. Os últimos ocorreram em 2017 e em 2018 - o "Simpósio de Estudos sobre o jambo, a elegia e a poesia mélica na Antiguidade Clássica" e a jornada "Estudos de poesia grega", respectivamente. Ambos contaram com a participação dos membros do GPq nas comunicações realizadas, em jornadas produtivas tanto para quem apresentou seus trabalhos quanto para quem esteve na audiência. O primeiro encontro repetiu-se em setembro deste ano, com o mesmo formato: "Jornada do Grupo de Pesquisa Estudos sobre o jambo, a elegia e a poesia mélica na Antiguidade Clássica”. Os encontros informais têm sido mais frequentes, aproveitando oportunidades criadas por cursos de pósgraduação e de extensão, bancas examinadoras de trabalhos, eventos científicos. A partir de 2020, o grupo passará a seguir um cronograma mensal de encontros, de modo a articular seu evento anual às discussões que lhe serão preparatórias.

Finda esta breve apresentação, faço um relato das pesquisas mais atuais do GPq, com apoio dos próprios pesquisadores que elenco a seguir, os quais foram os participantes da jornada do grupo em 27 de setembro de 2019. ${ }^{1}$ E concluo com o relato das pesquisas das líderes, isto é, de Paula Corrêa e a minha própria.

\footnotetext{
${ }^{1}$ Agradeço aos pesquisadores o envio de sínteses de seus trabalhos, que arrolo a seguir.
} 
A pesquisadora Nataly Ianicelli Cruzeiro, que neste ano ingressou no mestrado do Programa de pós-graduação em Letras Clássicas da USP (PPGLC), realizou pesquisa de iniciação científica (2017-2018) sob orientação da Profa. Paula Corrêa, financiada pela FAPESP, intitulada “Os Elementos de Harmonia de Aristóxeno de Tarento: estudo introdutório e tradução do livro I”. O objetivo do trabalho, segundo ela própria o descreve, foi realizar a tradução do primeiro livro do tratado para a língua portuguesa, acompanhada de notas e de um estudo introdutório acerca do método científico do tratado, observando o modo como aquele livro estabelece as bases para o pensamento de Aristóxeno a respeito da música e como ele se articula com os demais livros. Além disso, foi feito o mapeamento de procedimentos para a fundação de uma ciência da harmonia independente da aritmética, a qual utiliza em larga medida o método de organização do conhecimento disposto nos Analíticos posteriores, de Aristóteles. Com isso, resume a pesquisadora, chegou-se à conclusão de que Aristóxeno se vale do método científico aristotélico, mas discorda fundamentalmente de seu mestre em relação ao tratamento conferido à harmonia e é esse ponto preciso que permite a emancipação da ciência. Seu escopo, prossegue a pesquisadora, restringe-se ao estudo dos elementos estritamente musicais (notas, intervalos, escalas, gêneros etc.) e, para tanto, o analista musical deve se valer da percepção (aisthêsis) acurada e do pensamento (dianoia), a fim de considerar os fenômenos melódicos de modo adequado. Com isso, Aristóxeno aparta a harmonia das teorias matemáticas, tanto as aritméticas, quanto as geométricas, por considerá-las insuficientes para explicar a realidade musical e propõe que se estude somente a música praticável e correta do ponto de vista das leis naturais da harmonia.

No mestrado ora iniciado, com previsão de conclusão em 2021, a pesquisadora dá sequência ao trabalho da IC, novamente com apoio da FAPESP e sob orientação da Profa. Paula Corrêa, sob o título "Os Elementos de Harmonia de Aristóxeno: tradução, notas e um ensaio sobre compreensão e julgamento da música". Pretende a pesquisadora nesta etapa traduzir os outros dois livros do tratado, anotá-los e oferecer um ensaio sobre o conceito de compreensão (synesis) e análise musical.

$\mathrm{Na}$ tese de doutorado "A referencialidade tradicional na poesia de Safo de Lesbos", recentemente defendida na USP (PPGLC), sob orientação da Profa. Corrêa e com apoio de bolsa Capes, o Prof. Dr. Tadeu Andrade (UFBA) investigou como a poesia de Safo de Lesbos interage com a linguagem herdada e o arcabouço de elementos tradicionais da poesia grega arcaica. Trata-se de um trabalho desenvolvido em linha de continuidade com o trabalho precedente do mestrado realizado com apoio de Bolsa Fapesp e sob orientação do Prof. Dr. João Angelo Oliva Neto (USP), que se dedicou à linguagem e à poética de Aristófanes e da Comédia Antiga.

Como explica o pesquisador, a abordagem oralista da poesia épica arcaica (fundada pelos estudos de Milman Parry e Albert Lord) considera os poemas homéricos e hesiódicos como produtos de uma poética oral distinta da escrita, fortemente marcada por linguagem, cenas e enredos tradicionais, que pertencem à tradição como um todo e não se referem a um texto ou autor particulares. Primeiramente, esses elementos foram encarados como facilitadores de uma produção exclusivamente oral, sem a ajuda da escrita. Mais tarde, sobretudo 
nos estudos de John Miles Foley, pensou-se seu papel na recepsão da epopeia. Tal abordagem oralista-tradicional pouco foi levada aos gêneros poéticos arcaicos não-hexamétricos, como a elegia, o iambo e a mélica; o projeto conduzido pelo pesquisador no doutorado consiste justamente em empenhado esforço de análise do corpus mélico sáfico a partir dessa abordagem.

Nesse sentido, o pesquisador buscou saber se também a mélica lésbia era de fato marcada por expressões, temas e padrões tradicionais, identificáveis nos fragmentos de Safo e Alceu ou nos demais poetas mélicos, elegíacos e iâmbicos. Dado que a poesia mélica antiga se compunha de tipos de canção e lugares-comuns, constatou que essas unidades poderiam ser reinterpretadas sob o viés dos estudos orais. E comparando os fragmentos dos poetas lésbioeólicos com o corpus arcaico, verificou que empregavam fórmulas e expressões tradicionais, grande característica da poesia homérica e hesiódica e pedra angular dos estudos oralistas.

Identificados elementos tradicionais que aproximavam a prática poética de Safo à dos épicos, a pesquisa buscou, enfim, entender em que medida eram operados pela poeta para gerar significado, e para tanto realizou a análise detida de quatro fragmentos mais extensos (1, 16, 31 e o "Poema dos Irmãos"). Identificaram-se, depois, quais temas, expressões e tipos de canção se repetiam em poemas de Safo e outros poetas e, portanto, pareciam tradicionais. Compararam-se, enfim, os contextos de uso desses elementos, buscando identificar pressupostos semânticos associados a eles. O pesquisador realçou a frequência com que os contextos eram semelhantes, de modo que as unidades tradicionais pareciam carregar consigo implicações de sentido de que a poeta se servia para compor suas canções.

$\mathrm{Na}$ dissertação de mestrado "Prostituição feminina na mélica e jambo arcaicos: imagens e temas", sob minha orientação no PPGLC, Enrique Carretero procedeu à análise da representação da prostituição feminina e seus principais temas na poesia mélica e jâmbica grega arcaica (séculos VII-VI a.C.) e tardo-arcaica (séculos VI-V a.C.). O corpus contemplou quatorze fragmentos de quatro poetas mélicos - Alceu, Safo, Anacreonte e Píndaro - e dois jâmbicos - Arquíloco e Hipônax -, além de incluir discussões acerca de questões suscitadas pelo uso dos termos pórnè e "hetera", categorias com as quais se denominavam as mulheres que exerciam prostituição na Grécia antiga.

O principal resultado, afirma o pesquisador, advém da presença exclusiva do termo pórne - distintivo de "prostituta" - nos corpora arcaico e tardo-arcaico e da ausência de "hetera", que aparece pela primeira vez - em sentido relativo à prostituição - na época clássica (séculos V-IV a.C.), em Heródoto (Histórias II, 134-135). O entendimento de pórné e "hetera" como categorias opostas e claramente definidas - aquela, associada ao espaço da rua e dos bordéis, tendo como clientes homens não-pertencentes à elite, e esta, mais sofisticada, frequentadora do simpósio, mantendo relações de mais longo prazo e de caráter mais exclusivo, por assim dizer, com algum homem da elite, recebendo por isso compensação financeira mais robusta e duradoura - é substituído por um olhar mais abrangente que: a) apresenta diversos exemplos nos corpora clássico e helenístico (séculos IV-I a.C.) em que uma mesma mulher é tratada ora como pórnè, ora como hetera; b) sugere que a ausência do termo "hetera" nos corpora arcaico e tardo-arcaico parece refletir as características de uma sociedade em que a linguagem relacionada à sedução, sobretudo no âmbito do simpósio ou 
em contextos de sacrifícios religiosos, não admitia associação com atividade relacionada à prostituição; c) identifica o uso restrito de pórnè a situações de rebaixamento ou de invectiva nos corpora arcaico e tardo-arcaico.

Um dos corolários da pesquisa foi constatar indicativos de uma estreita relação entre prostituição e escravidão, havendo ao menos uma descoberta arqueológica que permite pensar que algumas escravas - de forma mais específica, da tecelagem -, teriam sido também prostitutas. A sequência mais provável da investigação, em etapa posterior de formação, indica o pesquisador, será verificar e traçar a presença dessa relação - prostituição e escravidão nos corpora arcaico e tardo-arcaico.

$\mathrm{Na}$ dissertação de mestrado "Perséfone e Hécate: a representação das deusas na poesia grega arcaica”, orientada por mim, e com bolsa Capes, Thais Rocha Carvalho teve por objetivo investigar a representação das deusas na poesia do período arcaico (VIII-V a.C.) - com maior enfoque no Hino Homérico a Deméter e na poesia de Hesíodo, mas também passando por outros autores e gêneros poéticos, bem como traçando paralelos com as esferas iconográfica e cultual -, de forma a resgatar a figuração primordial e a importância dessas divindades no mundo grego arcaico. Se comparadas a figuras mais proeminentes como Zeus e Atena, nota a pesquisadora, são poucas as menções que os poetas fazem a elas, mas suficientes para que possamos entender melhor seus papéis.

Esse trabalho consistiu em continuação e aprofundamento de pesquisa anterior, de iniciação científica, intitulada "Perséfone e Hécate na poesia grega arcaica", também orientada por mim, com bolsa Fapesp, cujo foco foram a Teogonia e o Hino Homérico a Deméter. Para o doutorado, iniciado neste ano de 2019, o projeto da pesquisadora volta-se à poesia dramática. Intitulado "Gámos e Thánatos: a relação entre o casamento e a morte na tragédia grega clássica", o estudo pretende avançar as investigações ao prosseguir com o tema das relações entre a morte e o casamento - no mestrado, trabalhado a partir da figura da deusa Perséfone -, enfocando sobretudo as heroínas das seguintes peças: de Ésquilo, Agamêmnon (Clitemnestra); de Sófocles, As Traquínias (Dejanira) e Antígone; de Eurípides, Ifigênia em Aulida, Medeia e Alceste.

$\mathrm{Na}$ tese de doutorado "Antifonia lírica em Sófocles: Édipo Rei, Electra, Filoctetes", Márcio M. Chaves Ferreira dá continuidade ao trabalho do mestrado, que resultou na dissertação "Os cantos de Sófocles: tradução e análise de gênero e metro das passagens líricas d'As traquinias, Ajjax e Antígona" - ambos apoiados com Bolsa Capes. Em tal dissertação, o pesquisador traduziu todos os passos líricos das peças e analisou cinco deles - peças que, segundo razoável consenso relativo à cronologia, formariam o grupo mais antigo da obra integral do tragediógrafo, sem que se leve em conta o problema de datação dos seus fragmentos. Desta vez, o pesquisador se propõe a traduzir e analisar determinadas passagens líricas das tragédias posteriores, mas anteriores a Édipo em Colono, que, também segundo certo consenso entre os estudiosos, é o último drama composto por Sófocles.

Ressalta Márcio Ferreira que uma mudança de foco em relação à dissertação reside na escolha do corpus selecionado, uma vez que a tese não se debruça sobre todas as passagens líricas das quatro tragédias, mas apenas sobre aquelas em que há a participação de ao menos 
mais um personagem além do Coro para com ele compartilhar o canto, ou, ainda que o Coro esteja ausente, a presença de mais de um personagem individual. Explica o pesquisador que o trabalho se divide em duas partes: uma de caráter mais geral, em que três temas considerados relevantes para a análise dos passos selecionados constituem os três capítulos dessa primeira parte; e outra, mais específica, em que as passagens serão analisadas em maior detalhe, já sob a luz do que se viu na primeira parte. Os três temas investigados na primeira parte da pesquisa são: (1) a tradição poética do lamento fúnebre, tanto nos poemas homéricos (góos), quanto na lírica arcaica (tbrênos); (2) o kommós segundo a definição de Aristóteles; e (3) o docmíaco e sua relação com os metros jâmbicos na lírica trágica. O primeiro tema aborda, portanto, uma questão de gênero poético (ou de subgêneros da lírica arcaica), e é escolhido em razão da prevalência que os lamentos assumem nessas passagens; o segundo trata de um problema de classificação, mostrando que o termo kommós, aplicado indistintamente aos passos líricos dialogados das tragédias por vários editores com base no capítulo 12 da Poética, não daria conta de sua variedade, se levarmos a sério a definição dada por Aristóteles; e o terceiro, diante da presença constante de um metro específico nas passagens escolhidas e pelo caráter tipicamente "lamentoso" que os estudiosos atribuem a esse metro, analisa os docmíacos com fundamento nos tratados antigos e modernos de métrica.

Os poemas que integram a segunda parte da tese já se encontram traduzidos, e resta agora comentá-los. São os seguintes: Édipo Rei, vv. 649-696, 1297-1365; Electra, vv. 86-250, 823-868, 1232-1285, 1398-1441; Filoctetes, 135-218, 828-864, vv. 1081-1217. A conclusão pretende refletir sobre os resultados da pesquisa e relacionar os pontos tratados separadamente em cada capítulo, levando em conta a tradição poética grega pré-dramática.

O projeto de pesquisa atual (Pq-CNPq 1D) da Profa. Paula Corrêa, "O Catálogo de mulheres; estudo, tradução e comentário", propõe a tradução, o estudo e o comentário de todos os fragmentos supérstites do Catálogo de Mulheres. São 296 fragmentos na edição de 1990 de Merkelbach e West, que serão cotejados e complementados pela edição de Most, de 2007, ressalta a pesquisadora. Embora os estudos de Corrêa nas últimas três décadas tenham por objeto a poesia mélica, jâmbica e elegíaca grega arcaica, na pesquisa atual a metodologia será a mesma, explica a pesquisadora, uma vez que o Catálogo é um poema composto provavelmente na mesma época que aqueles, isto é, pertence ao período arcaico e, a despeito dos diversos estilos, dicção e prosódia, chegou-nos de forma semelhante: em fragmentos papiráceos e em citas e/ou paráfrases em obras de variada natureza de outros autores ao longo da antiguidade clássica e tardia, o que exige a mesma abordagem. O projeto se justifica porque o Catálogo de Mulheres é importante e rica fonte de mitos, e foi justamente a sua relevância para a leitura de poemas jâmbicos, elegíacos e mélicos arcaicos, e a ausência de uma tradução para o vernáculo, que nortearam a concepção do projeto.

Quanto às minhas próprias pesquisas, cheguei neste ano à conclusão da terceira etapa de estudos da representação de Afrodite na mélica grega arcaica e tardo-arcaica. Depois de ter abarcado, nos últimos vinte anos, os corpora dos poetas arcaicos (Safo, Alceu, Álcman, Estesícoro, Íbico e Anacreonte) que trazem a deusa nas composições, centrei-me desta vez em Simônides (Frs. 541 e 575 Page) e Baquílides (Epinício 5, Ditirambo 17 e Fr. de encômio 
20B Maehler). Apresentando a tradução desse corpus e a análise detida das composições, tal qual nos estudos anteriores, e conduzindo os trabalhos com a mesma metodologia, explorei a ambivalência que caracteriza a imagem da deusa em Baquílides, e sua tendência mais acentuadamente negativa em Simônides. O resultado será apresentado em novembro na forma de tese em concurso de livre-docência na USP. Na quarta e última etapa, que será iniciada em 2020, as canções de Píndaro serão enfocadas para o estudo do mesmo tema da representação de Afrodite. Minhas publicações recentes, além de cursos e palestras, já resultam dos trabalhos com ambas as etapas.

Panorama GPq - "Estudos sobre jambo, elegia, mélica e música na antiguidade clássica" (https://sites.google.com/usp.br/grupodepesquisacnpq/p\%C3\%A1 gina-inicial) 